\title{
Effect of Solid Bases Catalyst on Conversion of Acrylonitrile into Acrylic Acid by Hydrothermal Reaction
}

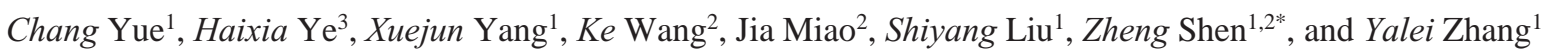 \\ ${ }^{1}$ State K ey Laboratory of Pollution Control and Resources Reuse, National Engineering Research Center of Protected A griculture, \\ Shanghai Engineering Research Center of Protected A griculture, Tongji University, Shanghai, 200092, China. \\ ${ }^{2}$ College of Civil Engineering and A rchitecture, Zhejiang U niversity of Technology, Hangzhou, 310014, China. \\ ${ }^{3}$ Shanghai Huajie Ecological Environment Engineering Co., Ltd., Shanghai, 201407, China
}

\begin{abstract}
This study aims at the shortcomings of the current industrial application of acrylonitrile wastewater treatment, using alkali-catalyzed hydrothermal technology to convert acrylonitrile into acrylic acid for achieving resource utilization. In this study, alkali metal, alkaline earth metal hydroxide and composite solid base were used as catalysts to investigate catalytic effects of these solid based on the hydrothermal reaction. The results show when using the alkali and alkaline-earth metal hydroxides as catalysts, the best effect of treatment was $\mathrm{KOH}$ and the highest yield of acrylic acid reached $56.60 \%$. It was also found that, among the three kinds of solid base catalysts (Ca-O-Mg, K-O-Al, K-O-Si) adopted with the same mass and various loading capacity, $\mathrm{K}-\mathrm{O}-\mathrm{Si}(15 \%)$ was the most effective catalyst for the conversion of acrylonitrile, and the highest yield of acrylic acid reached $57.78 \%$. This process provides an environmentally friendly method toward the synthesis of useful acrylic acid from acrylonitrile within a very short time.
\end{abstract}

\section{Introduction}

Acrylonitrile, an important chemical material, has been widely used in many areas, including the manufacturing of acrylonitrile butadiene styrene (ABS) plastic, nitrile rubber, acrylic fiber, synthetic resins and other chemical products $[1,2]$. It was reported that the global production capacity of acrylonitrile exceeds 5 million tons per year, of which about 1.4 million tons are produced in China [3]. The wastewater discharged during the production of acrylonitrile contains highly toxic substances, which are difficult to be degraded and are extremely harmful to the environment $[2,4]$. When the effluents discharged to receiving water, it may lead to a series of environmental impacts of water quality [5].

Currently, several methods are available to treating the acrylonitrile wastewater include incineration, radiation [6], ozonation [7], adsorption [8], biodegradation [9], electro-Fenton (EF) [10]. They are either limited by their high cost of operation or secondary pollutants generation. However, there exists some others methods which are wet air oxidation (WAO) [11], catalytic wet air oxidation (CWAO) [12] and supercritical water oxidation (SCWO) [13]. WAO is a decent way for treatment of effluents that are too dilute to incinerate and too concentrated for biological treatment, but it cannot completely mineralize the waste stream [12-14]. CWAO and SCWO also have the disadvantages of high equipment requirements. Therefore, a modified method, catalyst combined with the Supercritical Water, was used in this experiment. It enables conversion of acrylonitrile into acrylic acid with a comparatively high yield within a very short time.

Evidently, solid bases offer convenient and environmentally benign routes for organic synthesis [15]. They present fewer disposal problems while allowing easier separation and recovery. Furthermore, the solid bases present an excellent non-corrosion property [16]. In addition to that, the previous report showed a great improvement in alkenes and the relevant compounds isomerization when using the catalysts as alkali metals loaded on supports prepared by the metal vapor deposition $[17,18]$. So far, molecular sieve and aluminum oxide remain the two major types of supporter [19]. In this article, $\mathrm{KOH}$ was also confirmed as the best catalyst between several kinds of base catalysts. As a result, $\mathrm{CaO} / \mathrm{MgO}, \mathrm{KOH} / \gamma-\mathrm{Al}_{2} \mathrm{O}_{3}$ and $\mathrm{KOH} / \mathrm{SBA}-15$ were chosen to be the solid base catalysts in this research.

Our previous studies have studied that effective transforming high toxic acrylonitrile degradation into valuable chemical resource acrylic acid through alkaline hydrothermal system [20]. Therefore, the objectives of this article were to investigate the effect of conversion of acrylonitrile to acrylic acid by using different liquid bases as catalysts and to find a more environmentally friendly way to treat with the acrylonitrile wastewater by using solid bases as catalysts which were easy to be separated, to compare with the sufficiency of three types of base catalysts with different loadings.

\footnotetext{
* Corresponding author: 78shenzheng@ tongji.edu.cn
} 


\section{Materials and methods}

\subsection{Materials and experiment device}

Acrylonitrile (AR), acrylic acid (AR), $\mathrm{LiOH}(\mathrm{AR}), \mathrm{NaOH}$ (AR), $\mathrm{CaOH}(\mathrm{AR}), \mathrm{Mg}(\mathrm{OH})_{2}(\mathrm{AR}), \mathrm{KOH}(\mathrm{AR}), \mathrm{Sr}(\mathrm{OH})_{2}$ (AR), $\mathrm{Ba}(\mathrm{OH})_{2}(\mathrm{AR}), \mathrm{MgO}(\mathrm{AR})$ and calcium acetate (AR) were purchased from Sinopharm Chemical Reagent Co.,Ltd. Nano alumina ( $\gamma$ type, the aperture was $10 \mathrm{~nm}$, specific surface area less than $200 \mathrm{~m}^{2} / \mathrm{g}$ ) were purchased from Aladdin Industrial Corporation and SBA-15 (the aperture $7 \sim 8 \mathrm{~nm}$, specific surface area more than 1000 $\mathrm{m}^{2} / \mathrm{g}$ ) were purchased from JCNANO graphene standards.

Hydrothermal alkali catalysis experiments were carried out in a round tube batch reactor made of SUS316 stainless steel $(1 \mathrm{~mm}$ wall thickness, $120 \mathrm{~mm}$ long and $9.5 \mathrm{~mm}$ inner diameter stainless steel round). Before starting the reaction, weighed a certain amount of solid base into a stainless steel reactor, a certain volume of acrylonitrile solution and deionized water were simultaneously added to the reactor, and quickly seal the reactor. Then, the reactor was immersed in a salt bath preheated to the desired temperature for reaction. After that, the reactor was removed from the salt bath and immersed into a cold water bath. When the reactor cooled, opened the reactor and the liquid and solid products were washed out with deionized water.

This experiment investigated the conversion of acrylonitrile to acrylic acid with a solid base catalyst. Table1 shows the variation range of specific reaction parameters.

Table 1. Alkali-catalyzed hydrothermal reaction conditions of acrylonitrile

\begin{tabular}{|c|c|}
\hline Content & Conditions \\
\hline Reaction concentration & $30000 \mathrm{mg} / \mathrm{L}$ \\
\hline (1) Acrylonitrile & $2000 \mathrm{mg} / \mathrm{L}$ \\
\hline $\begin{array}{c}\text { Alkali metal, alkaline earth } \\
\text { metal hydroxide }\end{array}$ & $\begin{array}{c}(\text { Calculated by the OH}) \\
0.5 \sim 4 \mathrm{~mol} / \mathrm{L}\end{array}$ \\
\hline (2) Acrylonitrile & $2000 \mathrm{mg} / \mathrm{L}$ \\
\hline $\begin{array}{c}\text { Ca-O-Mg composite solid } \\
\text { base }\end{array}$ & $0.1 \mathrm{~g}(\mathrm{CaO}$ load $1.5 \sim 3 \%)$ \\
\hline (3) Acrylonitrile & $2000 \mathrm{mg} / \mathrm{L}$ \\
\hline $\begin{array}{c}\text { K-O-Al composite solid } \\
\text { base }\end{array}$ & $0.1 \mathrm{~g}(\mathrm{KOH} l o a d ~ 5 ~ 15 \%)$ \\
\hline (4) Acrylonitrile & $300{ }^{\circ} \mathrm{C}$ \\
\hline K-O-Si composite solid base & $0.1 \mathrm{~g}(\mathrm{KOH} \mathrm{load} \mathrm{5} \mathrm{15 \% )}$ \\
\hline Reaction temperature & $90 \mathrm{~s}$ \\
\hline Reaction time & $30 \%$ \\
\hline Fill rate & \\
\hline
\end{tabular}

\subsection{Preparation of composite solid bases}

\subsubsection{Preparation of $\mathrm{Ca}-\mathrm{O}-\mathrm{Mg}(\mathrm{CaO} / \mathrm{MgO})$}

$1.0 \mathrm{~g} \mathrm{MgO}$ was added to $10 \mathrm{ml}$ calcium acetate solution $(4.2 \mathrm{~g} / \mathrm{L}, 8.4 \mathrm{~g} / \mathrm{L}, 12.6 \mathrm{~g} / \mathrm{L})$ and then the mixture was stirred after standing for several hours and dried at $80^{\circ} \mathrm{C}$. Finally, the reaction mixture was calcined under 700 for 6 $\mathrm{h}$ and cooled to room temperature and well ground.

\subsubsection{Preparation of $\mathrm{K}-\mathrm{O}-\mathrm{Al}\left(\mathrm{KOH} / \mathrm{Y}-\mathrm{Al}_{2} \mathrm{O}_{3}\right)$}

$1.0 \mathrm{~g} \gamma-\mathrm{Al}_{2} \mathrm{O}_{3}$ was added to $10 \mathrm{ml}$ calcium acetate solution $(5 \mathrm{~g} / \mathrm{L}, 10 \mathrm{~g} / \mathrm{L}, 15 \mathrm{~g} / \mathrm{L})$ and then the mixture was stirred after standing for several hours, then dried under $70^{\circ} \mathrm{C}$. Finally, the reaction mixture burning under $400{ }^{\circ} \mathrm{C}$ for 5 $\mathrm{h}$, then cooled to room temperature and mashed.

\subsubsection{Preparation of K-O-Si (KOH / SBA-15)}

$1.0 \mathrm{~g}$ SBA-15 was added to $10 \mathrm{ml}$ calcium acetate solution ( $5 \mathrm{~g} / \mathrm{L}, 10 \mathrm{~g} / \mathrm{L}, 15 \mathrm{~g} / \mathrm{L})$ and then was added to the potassium hydroxide solution. The mixture was stirred after standing for several hours, then dried under $70^{\circ} \mathrm{C}$. Finally, the reaction mixture burning under $400{ }^{\circ} \mathrm{C}$ for 5 $\mathrm{h}$, then cooled to room temperature and mashed.

\subsection{Analytical methods}

The collected liquid samples were diluted by $\mathrm{HCl}$ aqueous solution $(2.0 \mathrm{M})$ and analyzed using LC-VWD (Agilent 1200 ) and GC-FID (Agilent GC 7820A). In the HPLC analysis, two RSpak KC-811 columns $(8.0 \mathrm{~mm} \times 300 \mathrm{~mm})$ in series were used for organic acid analysis with $2 \mathrm{mM}$ $\mathrm{HClO}_{4}$ as the eluent. Powder X-ray diffraction (XRD) pattern was used to ensure the successful fabrication of $\mathrm{Ca}-\mathrm{O}-\mathrm{Mg}, \mathrm{K}-\mathrm{O}-\mathrm{Al}, \mathrm{K}-\mathrm{O}-\mathrm{Si}$ and to evaluate the spent and regenerated catalysts. The yields of acrylic acid were calculated using the following equations (based on carbon): acrylic acid yield $(\%)=($ moles of acrylic acid obtained / moles of acrylonitrile taken) $\times 100 \%$.

\section{Results and discussions}

\subsection{Effect of alkali metal and alkaline earth metal hydroxides on the hydrothermal reaction of acrylonitrile}

In order to investigate the effect of alkali metal and alkaline earth metal hydroxides on the hydrothermal conversion of acrylonitrile to acrylic acid, the following set of experiments was done. The reaction conditions were: temperature $300^{\circ} \mathrm{C}$, time $90 \mathrm{~s}$, and alkali concentration was calculated based on the amount of hydroxide in the hydroxides of these alkali metals and alkaline earth metals. The results are shown in Fig.1 and Table 2.

As is shown in Fig.1, with different concentration of alkali metal hydroxide, the yield of acrylic acid increased from $0.5 \mathrm{~mol} / \mathrm{L}$, until reached the peak at $1 \mathrm{~mol} / \mathrm{L}$, then decline slightly. For alkaline earth metal hydroxide, 
almost all the alkaline increased from $0.5 \mathrm{~mol} / \mathrm{L}$, except $\mathrm{Mg}(\mathrm{OH})_{2}$ showed no significant influence. Furthermore, with the increased atomic radius, yields of acrylic acid declined rapidly. Fig.1 shows the effect of catalysis of alkali metal better than that of alkaline earth metal significantly. In addition, the acrylic acid is easier to be decomposed when the atomic radius of alkaline earth metal is larger.

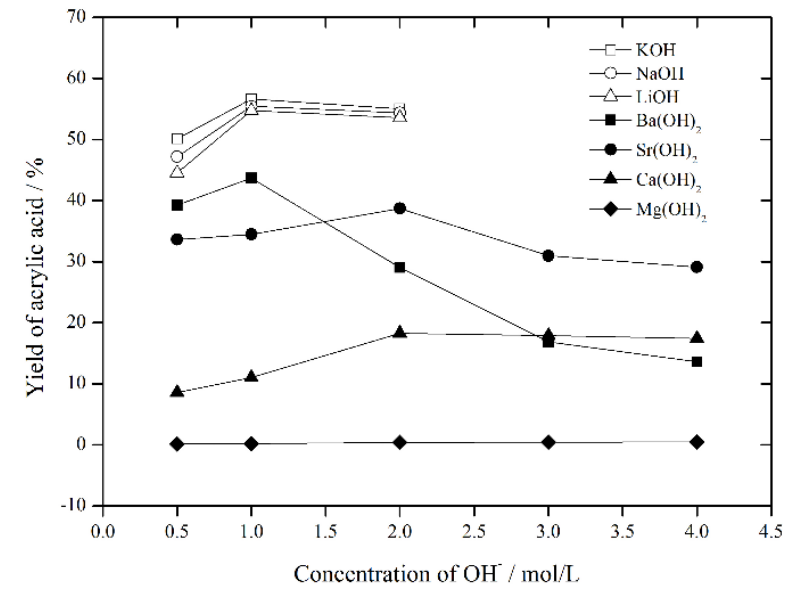

Fig.1. Effect of alkali metal and alkaline earth metal hydroxides on the yield of acrylic acid (T: $300^{\circ} \mathrm{C}$, t: $90 \mathrm{~s}$ )

It can be seen from Table 2 that $\mathrm{NaOH}, \mathrm{LiOH}$, $\mathrm{Sr}(\mathrm{OH})_{2}$ and $\mathrm{Ba}(\mathrm{OH})_{2}$ showed activity, albeit somewhat lower than that of the $\mathrm{KOH}$ with a satisfying yield. The species of alkaline catalysts have a major impact on the reaction. Clearly, the yields of acrylic acid were all over $50 \%$ when the alkaline metal was used as the catalyst, which was more efficient than alkaline earth metal catalysts. But the use of strong alkali restricts the further application of this process on a large scale. So, we look forward to a more environmentally friendly catalyst.

Table 2. The maximum yield of acrylic acid under the catalytic conditions of alkali metal and alkaline earth metal hydroxides

\begin{tabular}{|c|c|c|c|}
\hline $\begin{array}{c}\text { Alkali metal } \\
\text { hydroxides }\end{array}$ & $\begin{array}{c}\text { Maximum } \\
\text { yield of } \\
\text { acrylic acid }\end{array}$ & $\begin{array}{c}\text { Alkaline } \\
\text { earth metal } \\
\text { hydroxides }\end{array}$ & $\begin{array}{c}\text { Maximum } \\
\text { yield of } \\
\text { acrylic acid }\end{array}$ \\
\hline $\mathrm{LiOH}$ & $54.7 \%$ & $\mathrm{Mg}(\mathrm{OH})_{2}$ & $1.0 \%$ \\
\hline $\mathrm{NaOH}$ & $55.4 \%$ & $\mathrm{Ca}(\mathrm{OH})_{2}$ & $18.3 \%$ \\
\hline $\mathrm{KOH}$ & $56.6 \%$ & $\mathrm{Sr}(\mathrm{OH})_{2}$ & $38.7 \%$ \\
\hline & & $\mathrm{Ba}(\mathrm{OH})_{2}$ & $43.7 \%$ \\
\hline
\end{tabular}

\subsection{Characterization of solid base catalysts}

Recently, the development of solid base catalysts provides a greener, milder process, which is expected for the reaction of acrylonitrile. Instead of liquid bases, using solid base as catalysts provided an opportunity to decrease corrosion and related environmental issues. In addition, it allows easier for the separation and recycling of the catalyst. Thus, three efficient solid base catalysts were chosen and their effects on the reaction of acrylonitrile were explored. To understand the mechanisms of the improved performance of the different loading of solid base catalysts, XRD patterns of the films were investigated. It can be seen from Fig. 2(a)-(c) that when the loadings of the three catalysts are further increased, no obvious change of the intensity of the diffraction peak is observed.
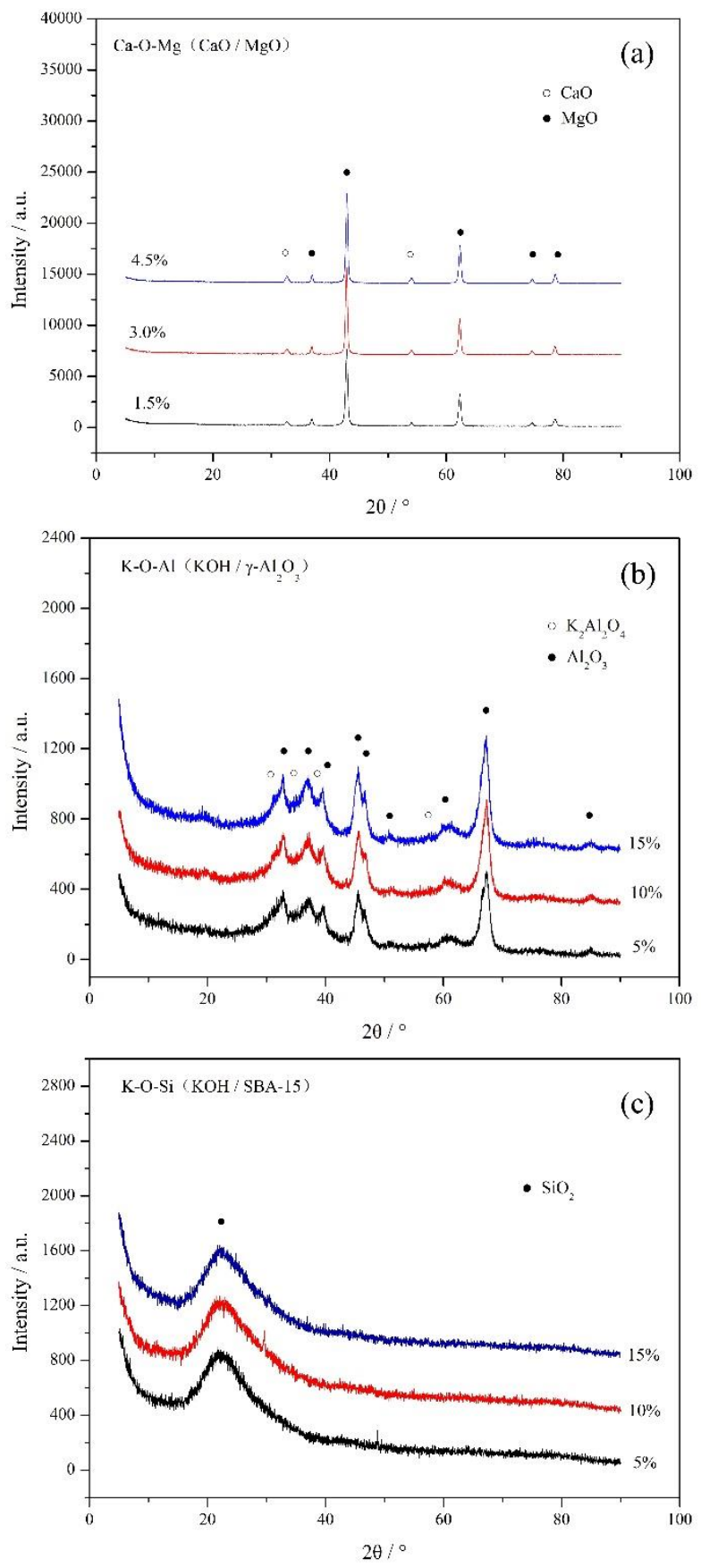

Fig.2. XRD patterns of (a) $\mathrm{Ca}-\mathrm{O}-\mathrm{Mg}(\mathrm{CaO} / \mathrm{MgO})$ film under different loading of $\mathrm{Ca}(\mathrm{OH})_{2}(4.5 \%, 3.5 \%, 1.5 \%$ up to down, $\left.700{ }^{\circ} \mathrm{C}, 6 \mathrm{~h}\right)$; (b) K-O-Al $\left(\mathrm{KOH} / \gamma-\mathrm{Al}_{2} \mathrm{O}_{3}\right)$ film under different loading of $\mathrm{KOH}\left(15 \%, 10 \%, 5 \%\right.$ up to down, $\left.400{ }^{\circ} \mathrm{C}, 5 \mathrm{~h}\right) ;(\mathrm{c})$ $\mathrm{K}-\mathrm{O}-\mathrm{Si}(\mathrm{KOH} / \mathrm{SBA}-15)$ film under different loading of $\mathrm{KOH}$ $\left(15 \%, 10 \%, 5 \%\right.$ up to down, $\left.400^{\circ} \mathrm{C}, 5 \mathrm{~h}\right)$.

Fig.2(a) shows $\mathrm{CaO} / \mathrm{MgO}$ (loading from $4.5 \%, 3.5 \%$, $1.5 \%$, respectively) film. Two diffraction peaks located at $2 \theta=32^{\circ}$ and $54^{\circ}$, which are attributed to the planes of 
$\mathrm{CaO}$, while four diffraction peaks at $2 \theta=37^{\circ}, 42^{\circ}, 62^{\circ}$ and $78^{\circ}$ appear in the film, which correspond to the planes of $\mathrm{MgO}$. In the beginning, calcium acetate completely decomposed into calcium oxide, carbon dioxide and hydrogen under $700{ }^{\circ} \mathrm{C}$. Then, the basicity of catalyst became stronger, and $\mathrm{Ca}-\mathrm{O}-\mathrm{Mg}$ would be formed in a pyroreaction of calcium oxide and magnesium oxide, as in equation (1).

$$
\begin{gathered}
\mathrm{Ca}\left(\mathrm{CH}_{3} \mathrm{COO}\right)_{2} \rightarrow \mathrm{CaO}+\mathrm{CO}_{2}+\mathrm{H}_{2} \mathrm{O} \\
\mathrm{CaO}+\mathrm{MgO} \rightarrow \mathrm{Ca}-\mathrm{O}-\mathrm{Mg}
\end{gathered}
$$

Fig.2(b) shows KOH/SBA-15 (loading from 15\%, $10 \%, 5 \%$, respectively) film. Noticing that only a diffraction peak at $2 \theta=21^{\circ}$, it indicated that there was $\mathrm{SiO}_{2}$ formed. The alkalinity increased since the catalyst impregnated with calcination. Lattice defect, because of high temperature burning, that leads to metal-doping. As a result, oxygen anions were bared and bond angles of metal were altered, that enhanced its power of electronics. $\mathrm{K}-\mathrm{O}-\mathrm{Si}$ would be formed in a reaction of potassium hydroxide and silicon dioxide at high temperature, as in equation (2).

$$
\mathrm{KOH}+\mathrm{SiO}_{2}(\mathrm{SBA}-15) \rightarrow \mathrm{K}-\mathrm{O}-\mathrm{Si}+\mathrm{H}_{2} \mathrm{O}
$$

Fig.2(c) shows $\mathrm{KOH} / \gamma-\mathrm{Al}_{2} \mathrm{O}_{3}$ (loading from $15 \%, 10 \%$, $5 \%$, respectively) film. Three strong intensity of the diffraction peaks at $2 \theta=31^{\circ}, 34^{\circ}, 36^{\circ}, 58^{\circ}$ is observed. It expressed that a new crystal-phase which known as K-O$\mathrm{Al}$ is generated. There are also detected other nine diffraction peaks located at $2 \theta=22^{\circ}, 25^{\circ}, 40^{\circ}, 46^{\circ}, 48^{\circ}$, $52^{\circ}, 60^{\circ}, 67^{\circ}, 85^{\circ}$, which are attributed to the planes of $\mathrm{Al}_{2} \mathrm{O}_{3}$. With the increase of the calcination temperature, lattice defect began to appear in catalyst. It enables three elements $(\mathrm{K}, \mathrm{Al}, \mathrm{O})$ doped with each other, followed by rising of the concentration of lattice oxygen $\left(\mathrm{O}^{2-}\right)$. The basicity of catalyst also became stronger, until approached the maximum at $400{ }^{\circ} \mathrm{C}$, then the basicity declined gradually. Under $400{ }^{\circ} \mathrm{C}, \mathrm{K}-\mathrm{O}-\mathrm{Al}$ would be formed in a reaction of potassium hydroxide and aluminium oxide, as in equation (3).

$$
\mathrm{KOH}+\mathrm{Al}_{2} \mathrm{O}_{3} \rightarrow \mathrm{KAlO}_{2}(\mathrm{~K}-\mathrm{O}-\mathrm{Al})+\mathrm{H}_{2} \mathrm{O}
$$

\subsection{Effect of solid base catalysts}

Under the same conditions, we compared the result of using three base catalysts. While compared the result of catalysts that using different carriers (SBA-15, $\gamma-\mathrm{Al}_{2} \mathrm{O}_{3}$ ) with the same dehydrogenation catalytic ingredient $(\mathrm{KOH})$ and same loading, the yield of acrylic acid of using SBA15 as carrier was higher than that of $\gamma-\mathrm{Al}_{2} \mathrm{O}_{3}$. It is illustrated that the basic property of the support seems to be important in the development of the high catalytic activity in $\mathrm{KOH} /$ support system.

In Table 3, it was easy to find that K-O-Si catalyst was more likely to achieve high yields. $15 \%$ load of K-O-Si shows the best catalytic effect with a yield of $57.78 \%$, which far exceeds that of $4.5 \%$ load of $\mathrm{Ca}-\mathrm{O}-\mathrm{Mg}$ $(36.07 \%)$. And compared among the three catalysts, the catalytic activity came in the order of $\mathrm{K}-\mathrm{O}-\mathrm{Si}>\mathrm{K}-\mathrm{O}-\mathrm{Al}>$ $\mathrm{Ca}-\mathrm{O}-\mathrm{Mg}$. In addition, compared with the best liquid bases catalyst $\mathrm{KOH}$, we researched before, which arrived a yield of $56.64 \%$. K-O-Si was more likely to give higher conversions with a higher yield of $57.78 \%$. Overall, comparing all the alkaline catalysts above in this article, it is clear that $\mathrm{K}-\mathrm{O}-\mathrm{Si}$ is more active over other catalysts.

Table 3. Comparison among different base catalysts. (Reaction conditions: $2 \times 10^{3} \mathrm{mg} / \mathrm{L}$ acrylonitrile, $0.1 \mathrm{~g}$ catalyst, $30 \%$ water filling, $300{ }^{\circ} \mathrm{C}, 90 \mathrm{~s}$.)

\begin{tabular}{|c|c|c|}
\hline Entry & Base catalyst & Yield \\
\hline 1 & Ca-O-Mg $(1.5 \%)$ & $29.81 \%$ \\
\hline 2 & Ca-O-Mg $(3.0 \%)$ & $35.33 \%$ \\
\hline 3 & Ca-O-Mg $(4.5 \%)$ & $36.07 \%$ \\
\hline 4 & K-O-Al $(5 \%)$ & $33.13 \%$ \\
\hline 5 & K-O-Al $(10 \%)$ & $37.54 \%$ \\
\hline 6 & K-O-Al $(15 \%)$ & $39.75 \%$ \\
\hline 7 & K-O-Si $(5 \%)$ & $43.80 \%$ \\
\hline 8 & K-O-Si $(10 \%)$ & $54.47 \%$ \\
\hline 9 & K-O-Si $(15 \%)$ & $57.78 \%$ \\
\hline
\end{tabular}

\subsection{Effect of different loading of solid base catalysts}

With the three catalysts in hand we investigated their catalytic performance in the reaction. The effect of K-OSi loading of $5 \%, 10 \%$, and $15 \%$ on the hydrothermal reaction of acrylonitrile was studied. After the reaction, the products were subjected to a series of dilution, centrifugation, acidification. The liquid phase products were analyzed as shown in Fig.3. An exciting discovery was made, when the catalyst loadings were increased from $5 \%$ to $10 \%$, three kinds of organics (acetic acid, acrylic acid and acrylamide) can be found in the product. Moreover, when the loading is up to $15 \%$, only acetate and acrylic acid can be detected. It indicated that increased loading, the by-products of acrylonitrile would be reduced. Such case also happened to using K-O-Al as catalysts. In addition, $\mathrm{Ca}-\mathrm{O}-\mathrm{Mg}$ catalyst was turned out to be poor efficient comparing with the other two catalysts, for four kinds of organics (acrylonitrile, acetic acid, acrylic acid and acrylamide) were generated with a lower loading, and three of them (acetic acid, acrylic acid and acrylamide) were still evidenced by using the highest one.

A gradual increase in acrylonitrile conversion was observed with the increase of all three loadings (Table 3). As well, the tendency of $\mathrm{pH}$ of the solvent accompanies with the increased loading was detected. When the loading of catalysts increased, the $\mathrm{pH}$ of the solvent also became higher, and a clearly increasing trend from $29.81 \%$ to $36.07 \%$ (Ca-O-Mg), $33.13 \%$ to $39.75 \%$ (K-O-Al), and $43.80 \%$ to $57.78 \%$ (K-O-Si) was observed for acrylic acid yields. But this increasing trend was slowed down, which showed a positive correlation with the increasing trend of $\mathrm{pH}$. When under the same ingredient of catalysis, loading became the main influence factor to the yields. 


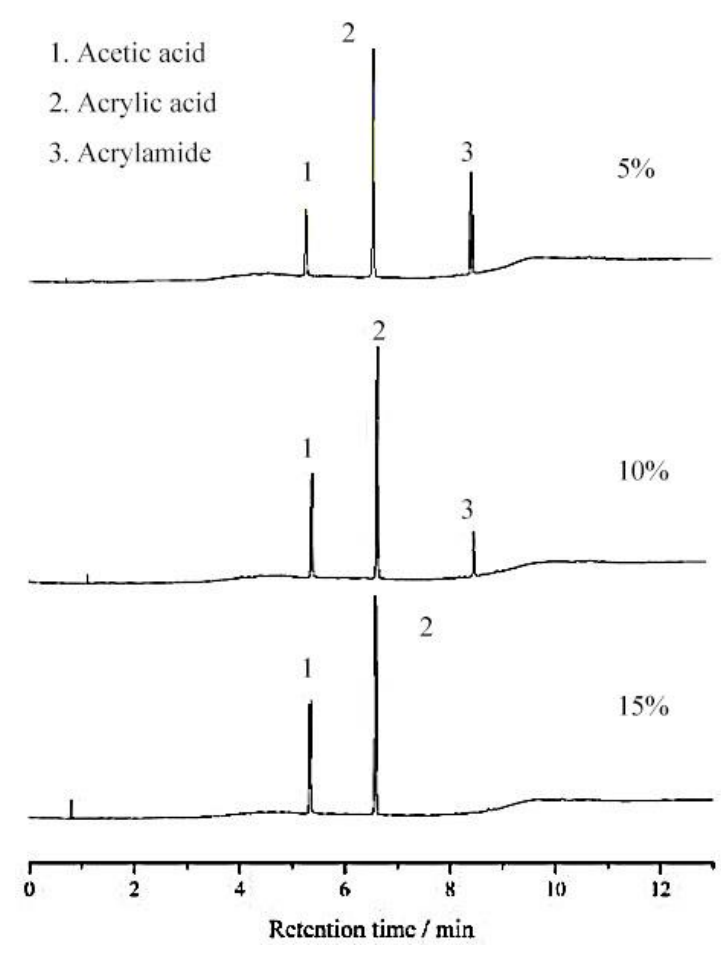

Fig.3. GC-FID patterns of $\mathrm{KOH} / \mathrm{SB}$ A-15 film under different loading of $\mathrm{KOH}(5 \%, 10 \%, 15 \%$ up to down, 400 ÎC, 5 h).

\section{Conclusion}

In this experiment, the influence of several different types of alkali on the hydrothermal reaction of acrylonitrile was studied. Four kinds of bases are selected: alkali metal alkaline earth metal hydroxide, $\mathrm{Ca}-\mathrm{O}-\mathrm{Mg}(\mathrm{CaO} / \mathrm{MgO})$ composite solid base, $\mathrm{KO}-\mathrm{Al}\left(\mathrm{KOH} / \gamma-\mathrm{Al}_{2} \mathrm{O}_{3}\right)$ composite solid base and KO-Si (KOH / SBA -15) Compound solid base. At a certain reaction temperature and time, the catalytic effect of the base was determined by examining the effect of different base additions on the yield of the target product acrylic acid.

The effect of using alkali metal hydroxide is significantly higher than that of alkaline earth metal hydroxide. Under the same reaction conditions, according to the yield of acrylic acid, according to the catalytic effect from high to low: $\mathrm{KOH}>\mathrm{NaOH}>\mathrm{LiOH}>\mathrm{Ba}(\mathrm{OH})_{2}>\mathrm{Sr}$ $(\mathrm{OH})_{2}>\mathrm{Ca}(\mathrm{OH})_{2}>\mathrm{Mg}(\mathrm{OH})_{2}$. When $\mathrm{KOH}$ is used, the maximum yield of acrylic acid is $56.60 \%$. Using $\mathrm{Ca}-\mathrm{O}$ $\mathrm{Mg}(\mathrm{CaO} / \mathrm{MgO})$ composite solid base under the reaction conditions of temperature $300{ }^{\circ} \mathrm{C}$ and time $90 \mathrm{~s}$, and when the loading is $4.5 \%$, the maximum yield of acrylic acid is $36.07 \%$. Using $\mathrm{K}-\mathrm{O}-\mathrm{Al}\left(\mathrm{KOH} / \gamma-\mathrm{Al}_{2} \mathrm{O}_{3}\right)$ composite solid base under the same reaction conditions, and when the loading is $15 \%$, the maximum yield of acrylic acid is $39.75 \%$. Using K-O-Si (KOH / SBA-15) composite solid base under the same reaction conditions, and when the loading is $15 \%$, the maximum yield of acrylic acid is $57.78 \%$. This shows that K-O-Si (KOH / SBA-15) composite solid base has the best catalytic effect.
This work was supported by National Key Research and Development Program of China (No. 2019YFC1906700), the National Natural Science Foundation of China (No. 21978224 and 21676205) and Agricultural Science and Technology Innovation Project of Chongming District (No. 2019CNKC-08).

\section{References:}

1. Dong, H., Wang, W., Song, Z., Dong, H., Wang, J., Sun, S., Zhang, Z., Ke, M., Zhang, Z., Wu, W.M., Zhang, G, Bioresour Technol., 239, 472-481 (2017)

2. Dai $Y$, Song $Y, T u X$, Jiang $Y, Y$ uan $Y$. W ater Res., 85, 216-225(2015)

3. Guo Y, Chang H, Wang Q, Shao C, X U J, ZJUTB 0699. A M B Express 8(1), 191 (2018)

4. Shin $Y H$, Shin N C, et al, Hazard Mater., 163(2), 1142-1147(2009)

5. M orales-M ora M A, M artinez-Delgadillo SA, RosaDominguez $E$, et al, Afinidad., 69(560), 283288(2012)

6. Sun H, Wang J, J Tsinghua Univ (Sci and Technol)., 9, 023(2009)

7. Doğruel, $S$, Dulekgurgen, $E$, Orhon, $D, J$ Chem Technol and Biotechnol., 81(3), 426-432(2006)

8. Kumar A, Prasad B, Mishra IM.J Hazard M ater., 150(1), 174-182(2008)

9. Li T, Bai R, Ohandja DG, Liu J, Biodegradation, 20(4), 569-580(2009)

10. K usvuran $E$, Gulnaz 0 , et al, J H azard M ater., 109(1), 85-93(2004)

11. Hii K, Baroutian S, Parthasarathy R, Gapes DJ, Eshtiaghi N, Bioers technol, 155, 289-299(2014)

12. K im KH, Ihm SK, J H azard M ater, 186, 16-34(2011)

13. Veriansyah B, Kim JD, J Environ Sci, 19, 513522(2007)

14. Fu Jie, K yzas, G eorge Z, Chinese J. Catal., 35(1), 17(2014)

15. Lopez DE, Goodwin J G, Bruce DA, et al, A ppl Catal A-Gen, 295(2), 97-105(2005)

16. Ono Y. J Catal, 216(1), 406-415(2003)

17. Pines H, W. M. Stalick, A cademic Press, 55, 508542(2012)

18. Haag WO, Pines H. J the A m Chem Soc, 82(2), 387391(2006)

19. W anchai K, Suwimol W, W orapon K, et al, Environ Chem Eng, 8, (2019)

20. Wenjie $D$, Boyu $P, K$ e $W$, Jia $M, W$ ei $Z, Y$ alei $Z$, Zheng S, Environ technol., 38, 13-14(2017)

\section{Acknowledgement}

